\title{
An interview with Professor David Jayne at the NCRI 2017 Cancer Conference
}

\author{
David Jayne ${ }^{*, 1}$ \\ ${ }^{1}$ Academic Surgery, Leeds Institute of Clinical \& Biological Sciences, University of Leeds, Leeds, UK \\ *Author for correspondence: d.g.jayne@leeds.ac.uk
}

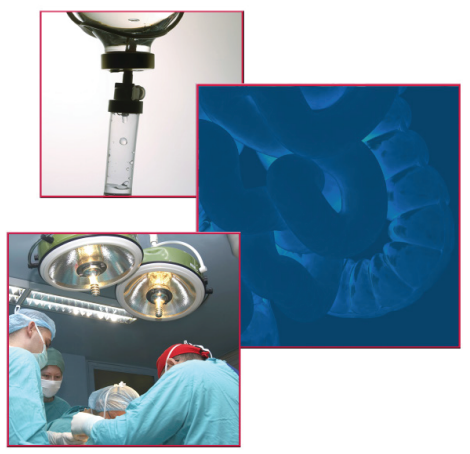

"the most significant change has been the introduction of minimally invasive or laparoscopic surgery."

David Jayne* speaks to Roshaine Wijayatunga, Managing Commissioning Editor: David Jayne is the Professor of Surgery at the University of Leeds and a Consultant General Surgeon at St James's University Hospital. He has a specialist interest in laparoscopic and minimal access surgery and is one of the few surgeons in the UK with experience in surgical robotics for abdominal disorders. He also has an interest in pelvic floor dysfunction, including the treatment of fecal incontinence and constipation. David has an active research interest in both these areas of surgical practice, which has led to the publication of many original research papers and two books. He sits on several NIHR funding bodies, is Clinical Director for the NIHR Healthcare Technology Co-operative in Colorectal Therapies and Co-Director for the NIHR Global Health Research Group in Surgical Technologies.

First draft submitted: 5 November 2017; Published online: 18 January 2018

Keywords:general surgery • laparoscopic • robotics

What led to your interest in coloproctology \& surgery?

I was influenced at an early stage while I was a House Officer in Surgery by an inspirational Professor who was interested in colorectal surgery and that stirred my interest and ambition.

How have you seen this field advance through your career: particularly with the improvement of technology \& robotics?

Colorectal surgery has advanced on a number of levels over the past 15-20 years and probably the most significant change has been the introduction of minimally invasive or laparoscopic surgery. We have moved away from doing operations through big abdominal cuts to doing operations through keyhole incisions. This has had tremendous advantages for patients and we are still accumulating the evidence regarding the oncological outcomes.

You have many research interests, including the development, application \& evaluation of new surgical technologies. You are also the Clinical Director for an NIHR Healthcare Technologies Co-operative. What is the aim of this Co-operative \& what are your specific roles?

The NIHR Healthcare Technology Co-operative is one of eight funded by the UK Department of Health to try and facilitate the pull through of new technologies into clinical practice for patient benefit. Our Healthcare Technology Co-operative is focused on colorectal surgery. I am pleased to say that we have just had our funding renewed for the next 5 years so we will now become the NIHR Medical Devices and in vitro Diagnostics Co-operative (MIC) in surgical technologies focusing more broadly on all surgical technologies. 
You co-hosted the session at the National Cancer Research Institute (NCRI) this year on 'Rectal cancer: top down, bottom up, robotic, laparoscopic or open?' How fierce is the debate in this area? Can you please tell us a little about the points presented \& discussed during this session?

Rectal cancer is entering a fascinating era, really driven by the new technologies that are being introduced, and currently, the evidence for performing rectal cancer surgery one way or the other is highly controversial. The traditional way of operating is with a big open cut, which was superceded by laparoscopic surgery, and more recently by robotic systems, the robot has potential advantages that may help in certain types of rectal cancer surgery. A further advance has been transanal surgery, where the whole operation is done through the back passage in a 'bottom-up approach'. We are accumulating evidence through registries regarding the safety of this approach. The other side of the story in rectal cancer management is advances in chemoradiotherapy, such that we now have a large proportion of our patients who have excellent responses to chemoradiotherapy, with no evidence of cancer remaining. The debate continues as to whether such patients actually need a big operation if their cancer has disappeared.

\section{With the continued advancement of medical robotics \& computer-assisted surgery, how do you see the field of colorectal surgery evolving in the next 5-10 years?}

There is no doubt that robotics will have an increasing role across surgery, not just in colorectal surgery. In colorectal surgery the area of interest is undoubtedly going to be in rectal cancer. I think we are entering a very exciting era where we have several robotics manufacturers now entering the market. The big obstacle in the past has been the cost of the robotic systems, and with the market opening up and much more competition, then hopefully we will see the prices driven down and the whole technology area opening up so more people can actually benefit.

\section{Disclaimer}

The opinions expressed in this interview are those of the interviewee and do not necessarily reflect the views of Future Medicine Ltd.

Financial \& competing interests disclosure

The author has no relevant affiliations or financial involvement with any organization or entity with a financial interest in or financial conflict with the subject matter or materials discussed in the manuscript. This includes employment, consultancies, honoraria, stock ownership or options, expert testimony, grants or patents received or pending, or royalties.

No writing assistance was utilized in the production of this manuscript. 